\title{
Rubén Darío y la Renovación de la Prosa Castellana
}

\author{
"O rinnovarsi o morire". \\ D'ANNUNZIO
}

$\mathrm{H}^{\mathrm{N}}$ su manifiesto literario de 1896, "Los colores del estandarte", 1. Rubén Darío habla de la renovación estilística que él mismo llevó al castellano: "La evolución que llevara al castellano a ese renacimiento, habría de verificarse en América, puesto que España está amurallada de tradición, cercada y erizada de españolismo. 'Lo que nadie nos arranca, dice Valera, ni a veinticinco tirones' ". ${ }^{1}$ No han exagerado ni Darío ni Valera. Como bien observa el dariísta italiano Vittorio Borghini, "gli scrittori spagnoli, a differenza dei francesi, avevano sempre studiato scarsamente la loro lingua e il loro stile, considerando siffato studio quasi superfluo". 2 Testigo de esta actitud de fuerte tradicionalismo hacia toda innovación estilística es Enrique Gómez Carrillo. Ẽste, en su ensayo "El arte de trabajar la prosa artística", se ensaña con los preceptistas y dice:

En cuanto a las modernas y caprichosas maneras harmónicas, prohibidas. La frase corta, nerviosa y desarticulada, la frase que salta, y ríe, y goza, prohibida. $Y$ prohibidas también la frase mármol a lo Saint-Víctor, la frase color a lo Flaubert, la frase orquesta a lo

1 Julio Saavedra Molina, Rubén Dario. Poesias y prosas raras (Santiago, 1938), pp. 68-69. "Los colores del estandarte" se publicó en La Nación de Buenos Aires el 27 de noviembre de 1896. Es un artículo que explica el credo estético de Darío frente a los ataques de Paul Groussac (1848-1929), director de la revista bonaerense, La Biblioteca. Groussac había escrito en esta revista, en noviembre de 1896, un artículo no "blandílocuo" acerca del libro de Darío, Los raros (1896).

2 Rubén Dario e il modernismo (Génova, 1955), p. 245. 
d'Annunzio. Todo eso es "decadente", "exótico", o "afectado". Lo único castizo, según nuestros maestros, es la tibia y larga frase llena de incidentes y de eslabones. "Es el estilo gramatical", dicen. Sí; está bien. Pero con estilos así es imposible llegar a producir obras cual las del divino Loti, para quien "la palabra más pura es la más harmónica" y que sabe proclamar "que la gramática y la belleza son enemigas". 3

Es en r905, en España, cuando salen a luz estas palabras de Gómez Carrillo.

Pero ya en : 888 , con la publicación de $A z u l$... en Valparaíso, Chile, los preceptistas se habían asombrado ante el fenómeno de una prosa renovadora, si no revolucionaria. No es que no hubiera "audaces" prosistas antes de $\mathbf{1} 888$, sino que el libro $A z u l$... marca un punto crítico en la historia de la prosa castellana. En Historia de mis libros (I9I3), Darío nos dice: "Cuando publiqué los primeros cuentos y poesías que salían de los cánones usuales, si obtuve el asombro y la censura de los profesores, logré en cambio el cordial aplauso de mis compañeros". ${ }^{4} \mathrm{Azul}$... debe considerarse como el punto de partida del movimiento modernista, cuyo principal aporte al castellano fue la rehabilitación de las formas expresivas del lenguaje. Este libro "primigenio" de Dario dio la nota inicial para la reforma de la prosa castellana, reforma que se esperaba desde bacía dos centurias. A este propósito dice Amado Alonso:

Rubén Darío sacaba de su segunda visita a la Península [en I899] la triste convicción de que en nuestra literatura no hallaba más que un solo estilo. $Y$ era el mismo de todos los escritores del siglo XIX y del xviri, que tenía un mimético parecido con los factores comu-

3 El modemismo (Madrid. 1905), p. 304. En este ensayo G. Carrillo revela su gran admiración por los artistas de la prosa en Francia, artistas que supieron librarse de la tiranía de los gramáticos. Lamenta que los preceptistas de la lengua castellana sigan firmes en su resistencia a toda innovación: "Nuestros gramáticos, siendo poco artistas, han secado la fuente viva de nuestra lengua literaria, obligándonos a no salir de moldes tradicionales... Por eso somos nosotros los únicos que no podemos decir que "el idioma es como un bosque donde, al lado de lo definido, hay lo que crece, lo que se forma, lo que viene con la nueva savia?"." Hemos subrayado lo conveniente.

4. El viaje a Nicaragua $e$ Historia de mir libros, t. XVII de las Obras completas (Madrid, 1917-1919), p. 170. Historia de mis libros es el nombre que la revista bonaerense, Nosotros, dio a tres ensayos de Darío sobre Azul..., Prosas profanas, y Cantos de vida y esperanza. Estos ensayos, enviados por Darío desde París en junio de 1913, aparecieron en La Nación de Buenos Aires en julio de 1913. En febrero de 1916, la revista Nosotros los reprodujo con este título general. 
nes de los estilos clásicos: durante dos centurias, todos nuestros estilos literarios, anacrónicamente mellizos. En esos doscientos años, nuestra prosa literaria no había hecho sino empobrecerse, porque le faltaron los esfuerzos personales de los escritores por superar las formas expresivas recibidas, muchas de las cuales, por ley biológica, habían envejecido o caducado. Sin nuevos jugos, se habia vuelto sarmentosa, demasiado definida de artistas $y$ perfiles [El subrayado es nuestro]. ${ }^{5}$

Ya desde la publicación de $A z u l \ldots$ en 1888 , Darío se propuso llevar a cabo - no solo, sino con la ayuda de los "modernos" de América y de España- la rehabilitación de la prosa castellana.

En este estudio nos limitaremos a descubrir la gran importancia que tuvo Darío en esa renovación de la prosa castellana. Examinaremos sus principales fuentes de inspiración para tal reforma, sus "precursores" en cuanto a la prosa artística, su propio programa de reforma literaria y, finalmente, su relación con la llamada generación de 1898 .

¿Cuáles fueron las principales fuentes de inspiración para el "revolucionario" libro Azul...? ¿De dónde arranca la novedad de este libro? En Historiat de mis libros, Dario nos dice:

El origen de la novedad fue mi reciente conocimiento de autores franceses del Parnaso, pues a la sazón la lucha simbolista apenas comenzaba en Francia y no era conocida en el Extranjero, y menos en nuestra América. Fue Catulle Mendès mi verdadero iniciador, un Mendès traducido, pues mi francés todavia era precario. Algunos de sus cuentos lírico-eróticos, una que otra poesía, de las comprendidas en el Panasse contemporaine, fueron para mí una revelación. Luego vendrían otros anteriores y mayores: Gautier, el Flaubert de

5 "Paul Groussac, estilista", en Nateria y forma en poesía (Madrid, 1955), p. 399. En España contemporánea, Darío, exceptuando a Valera y a los "nuevos", se queja del "estilo común" de los escritores españoles. Sus propias palabras: "A pesar del cansancio natural que produce este estilo común a todos los escritores peninsulares - hoy en vías de adquirir, por los nuevos, flexibilidad y variedad-, la prosa de Valera se lee con el agrado que se deriva de su inconfun. dible distinción". Ver "Novelas v novelistas" (que lleva la fecha del 24 de julio de 1899) en España contemporánea, t. XIX de las Obras completas (Madrid, 1917-1919), p. 181. 
La tentation de St. Antoine, Paul de Saint-Victor, que me aportarían una inédita y deslumbrante concepción del estilo. Acostumbrado al eterno clisé español del siglo de oro, y a su indecisa poesía moderna, encontré en los franceses que he citado una mina literaria por explotar: la aplicación de su manera de adjetivar, de ciertos modos sintáxicos, de su aristocracia verbal, al castellano. Lo demás lo daría el carácter de nuestro idioma y la capacidad individual. Y yo, que me sabia de memoria el Diccionario de galicismos de Baralt, comprendí que no sólo el galicismo oportuno, sino ciertas particularidades de otros idiomas son utilísimas y de una incomparable eficacia en un apropiado trasplante. ${ }^{6}$

Vale la pena hacer algún comentario sobre estas palabras de Dario. Es evidente que, para Darío, la novedad de su libro arranca de su deseo de adaptar procedimientos de origen francés al idioma castellano; es el "trasplante" de esos giros y formas expresivas al castellano lo que da a Azul ... su carácter innovador. No nos cabe duda de que Darío ha dado en el blanco al señalarnos, en I9r3, el origen de la novedad de su propio libro.

Otro detalle que deberíamos señalar es que en su historia del libro Azul..., Darío no ha citado sino unos cuantos parnasianos que influyeron en su libro. No nos ha ofrecido una enumeración completa, ni mucho menos. Darío, voraz lector, había leído a casi todos los autores franceses de la segunda mitad del siglo xIx. En su "Prólogo" a Azul..., Juan Valera nos da más pormenores sobre los autores franceses que leía Dario: "Lo primero que se nota es que está usted saturado de la más flamante literatura francesa. Hugo, Lamartine, Musset, Baudelaire, Leconte de Lisle, Gautier, Bourget, Sully Prudhomme, Daudet, Zola, Barbey d'Aurevilly, Catulo Mendès, Rollinat, Goncourt, Flaubert y todos los demás poetas y novelistas han sido por Ud. bien estudiados y mejor comprendidos. Y Ud. no imita a ninguno: ni es Ud. romántico, ni naturalista, ni 'neurótico', ni decadente, ni simbólico, ni parnasiano. Usted lo ba revuelto todo; lo ba puesto a cocer en el alambique de su cerebro, y ba sacado de ello una rara quinta esencia'.? A pesar del elogio que

6 Historia de mis libros, Pp. 170.171.

7 Citamos del "prólogo" de Valera que se encuentra en Julio Saavedra Molina y Erwin K. Mapes, Obras escogidas de Rubén Dario publicudas en Chile (Santiago de Chile. 1939), p. 200. Esta obra contiene la edición "crítica" de $A z u l \ldots$ Es Darío quien teproduce, para la segunda edición de Azul... (1890), dos artículos de Valera en forma de cartas que se publicaron, por primera 
Valera le hace a Darío a causa de su originalidad, éste -en sus notas a la segunda edición de $A z u l \ldots$ en r890-sigue firme en la convicción de que su arte obedece a una inspiración esencialmente parnasiana. ${ }^{8}$ No obstante, nosotros creemos que es mejor considerar a Darío como escritor sincrético que incorpora en su arte todos los recursos de la técnica literaria francesa del momento; no cabe clasificar su arte en una sola modalidad literaria. En fin, es polémica inútil reparar en pelillos para comprobar si Darío era, en los años en que componía $A z u l \ldots$. . parnasiano o simbolista decadente. ¿Qué importa? ¿Qué valor tiene esta discusión? Siete años más tarde, ya seguro de sí, el mismo Darío proclamará: "E1 verdadero artista comprende todas las maneras y halla la belleza bajo todas las formas"."

Tenemos un valiosísimo documento que antecede a la publicación de $A z u l$... y en el que Darío, de modo indirecto, nos explica sus propias ideas estéticas en cuanto a la "buena" prosa. Ensalza en este manifiesto al poeta y cuentista francés, Catulle Mendès; lo considera, a fin de cuentas, como parnasiano y "decadente" a la vez, ya que es difícil "establecer diferencia entre parnasianos y decadentes". El artículo de Darío vio la luz en el diario santiaguino La Liberiad Electoral el 7 de abril de 1888, y lleva por título "Catulo Mendez [sic.] Parnasianos y decadentes". No hay palabras más exactas que éstas para describir el arte de la prosa en $A z u l \ldots$...

Creen y aseguran algunos que es extralimitar la poesía y la prosa, llevar el arte de la palabra al terreno de otras artes, de la pintura verbigracia, de la escultura, de la música. No. Es dar toda la sobe-

vez, en El Imparcial, diario de Madrid, los días 22 y 29 de octubre de 1888. En esta segunda edición de $A z u l \ldots$... el "prólogo" de Valera antecede al de Eduardo de la Barra, a pesar de que el crítico chileno había escrito su "prólogo" antes en el diario santiaguino, La Tribuna, números del 20 al 23 de agosto de 1888. Lo subrayado de la cita es truestro.

8 Dice Darío en las notas de 1890: "Admiro el delicado procedimiento de esos refinados artistas que hoy tiene Francia [se refiere a los "decadentes", o simbolistas], pero bien "sé hasta dónde llegan sus exageraciones y exquisiteces. Entre José Maria de Heredia, parnasiano, y Mallarmé, Valbrègue, u otros de los decadentes, the quedo con el rey de los sonetistas" (Obras escogidas, p. 379).

Darío no es parnasiano a la letra, como él quisiera creer. La prosa de Azul..., por cierto, no muestra esa frialdad, esa falta de "subjetivismo" que era el ideal de la escuela parnasiana en sus primeros momentos bajo Leconte de Lisle. Como ha podido demostrar Eduardo de la Barra, el original prologuista de $A z u l . .$. , hay un fondo lírico, subjetivo, en los cuentos, cuyo protagonista es el poeta, con sus cuitas, desilusiones y fantasías.

9 "La cita es de "Dilucidaciones", prólogo a El canto errante (Madrid, 1907). Citamos de Rubén Dario. Poesías completas, edición de Alfonso Méndez Plan. carte (Madrid, 1954), p. 796. 
ranía que merece al pensamiento escrito, es hacer del don humano por excelencia un medio refinado de expresión, es utilizar todas las sonoridades de la lengua en exponer todas las claridades del espíritu que concibe... Juntar la grandeza o los esplendores de una idea en el cerco burilado de una buena combinación de letras; lograr no escribir como los papagayos hablan, sino hablat como las águilas callan; tener luz y color en un engarce, aprisionar el secreto de la música en la trampa de plata de la retórica, hacer rosas artificiales que huelen a primavera, he aquí el misterio. $\mathrm{Y}$ para eso, nada de burgueses literarios, ni de frases de cartón. ${ }^{10}$

En el mismo artículo, Darío, ahora directamente, alaba el arte de Mendès. Las palabras de Darío sobre el francés son una defensa de sus propios ideales en cuanto a la prosa castellana:

Un orífice pintor, un músico que esculpe, un paisajista fotógrafo y hasta químico y siempre poético y -aquí está la palabraun poeta con el don de una universalidad pasmosa, he aquí a Catulo Mendez... Tiene el instinto de adivinar el valor hermoso de una consonante que martillea sonoramente a una vocal; y gusta de la raiz griega, de la base exótica, siempre que sea vibrante, cxpresiva, melodiosa. Sabe que hay vocablos maravillosamente propensos a la armonía musical. Las letras forman, por decir así, sus cristalizaciones en el lenguaje. Las eles bien alternadas con eres y enes, enlazando ciertas vocales, la $q$, la y griega, son propicias a las palabras melódicas. Hay letras diamantinas que se usan con tiento, porque, si no, se quiebran formando hiatos, angulosidades, cacofonías y durezas. ${ }^{11}$

Todas estas palabras del artículo sobre Catulle Mendès muestran el afán de Darío para producir en castellano una prosa pictórica, musical y poética - en una palabra, una prosa artística-tal como existía en Francia donde los escritores se revelaban como máximos artífices de su idioma.

Es interesante notar que, hacia 1893 , Darío, ya consciente de su alta misión en la renovación de la prosa castellana, compone unos versos en que

10 Raúl Silva Castro, Obras desconocidas de Rubén Davio escritas en Cbile y no recopiladas en ninguno de sus libros (Santiago de Chile, 1934), p. 168 y p. 170.

11 Obras desconocidas, p. 171. 
defiende la maestría de su nuevo arte y la aristocracia de su expresión sonora y musical; se muestra también un defensor apasionado del "arte por el arte":

Arte es religión. Creamos

en el arte, en él pensemos;

a sus altares llevemos

nuestras coronas y ramos.

Hagamos de la expresión

que siempre harmonía sea, y hagamos de cada idea una cristalización.

La prosa es el material; adorno, las frases mismas; y las letras son los prismas del espléndido cristal.

$Y$ dejemos sus enfáticas reglas y leyes teóricas, a los que escriben retóricas

y se absorben las gramáticas.

Pensar firme; hablar sonoro; ser artista, lo primero; que el pensamiento de acero tenga ropaje de oro. ${ }^{12}$

Estas redondillas de Darío van dirigidas a su amigo cubano, el maestro Desiderio Fajardo Ortiz; se encuentran en un ejemplar de $A z u l .$. que Darío regaló al cubano.

Y más. En "Dilucidaciones" (prólogo a El canto errante, Madrid, 1907), Darío explica bien a las claras que su arte se opone a los viejos cánones de la retórica tradicional: "El predominio en España de esa especie de retórica, aún persistente en señalados reductos, es lo que combatimos los que luchamos por nuestros ideales en nombre de la amplitud de la cultura $y$ de la libertad". ${ }^{13} \mathrm{Y}$ hay que reparar en que la

Poesiats completas, pp. $1075-76$

13 Poesias completas, p. 788. 
polémica de Darío no iba, en verdad, contra el pasado, sino "contra el presente, contra un presente burgués de clisés, lugares comunes, perezas y pequeñas satisfacciones". 14

La dirección de la renovación estilística de la prosa castellana se cristalizó de manera segura en Darío "no sólo, dice E. Anderson Imbert, por la mayor fuerza de su genio, sino también porque de pronto se propuso un programa". ${ }^{15}$ Esa renovación estilística, por una ley natural de cambios estéticos, había de realizarse a la fuerza. "La época, dice Andrés González-Blanco, pedía a gritos el nuevo pan de vida; se habían agotado los manantiales de léxico y de estilo que dieran vigor a la literatura castellana; urgía una renovación total del verso y de la prosa. En $A z u l \ldots$, Rubén Darío comenzó por desentumecer la prosa". ${ }^{16}$

\section{III}

Ahora bien, ¿quiénes son los "precursores" de Darío en cuanto a la prosa artística o poética? Como veremos a continuación, la América hispana nos of rece, en la segunda mitad del siglo XIX, una lista bastante numerosa de artistas que trabajan la prosa con arte. En su agudo ensayo, "La prosa poética de José Marti", Enrique Anderson Imbert nos da una breve historia de los prosistas artísticos de América que anteceden a Rubén Darío:

Si nos limitamos al género narrativo podríamos señalar, en la primera generación romántica, la novela idílica El capitán de Patricios de Juan María Gutiérrez (Argentina; 1809-1878); y, en la segunda generación romántica, relatos de Carlos Guido y Spano (Argentina; I827-I918), Juan León Mera (Ecuador; 1832-1894), Ignacio Manuel Altamirano (México; I834-I893), Jorge Isaacs (Colombia; I837-1895), Eugenio María Hostos (Puerto Rico; is 839-1903) y Juan Montalvo (Ecuador; I832-1889), el mayor de todos, el de más deslumbrante don de frase. ${ }^{17}$

$Y$ luego Anderson Imbert se detiene en examinar la generación

14 Enrique Anderson Imbert, Historia de la literatura bispanoamericana, t. I (México, 1961), p. 367.

15 Historia, p. 367.

16 Estudio preliminar, en Obras escogidas de Rubén Dario, t. I (Madrid, 1955), p. 298.

17 Estudios sobre escritores de América (Buenos Aires, 1954), p. 127. 
de prosistas que siguen de cerca las corrientes artísticas del parnasismo francés:

Desde r880 brota en las letras hispanoamericanas un nuevo grupo de prosistas que conocen y practican las novedades parnasianas. No se ha reparado lo suficiente en que la renovación literaria que se llama "modernismo" comenzó antes en la prosa que en el verso; y que comenzó con Eduardo Wilde (Argentina; I844-I9I3), Paul Groussac (Francia-Argentina; r848-r929), Eugenio José Varona (Cuba; I849-1933), Manuel González Prada (Perú; I848-I9I8), Justo Sierra (México; I848-I9r2), Manuel Gutiérrez Nájera (México; I859-1895), y José Martí (Cuba; I853-I895), el mayor, el más portentoso, situado, en la historia de la narración de tono poético, entre otros dos gigantes, Montalvo y Rubén Darío. ${ }^{18}$

Como dice A. Torres-Ríoseco, "Martí fue uno de los precursores de Darío en la renovación de la prosa castellana, pues ya desde I87I, año en que escribió su famoso Presidio político en Cuba, se aparta el gran cubano de la retórica tradicional romántica, para expresarse en una forma de gran intensidad realista, de vigorosos trazos, llena de color, de titmo y vibración". "in En cuanto al mexicano Manuel Gutiérrez Nájera es necesario advertir que, a pesar de su preferencia por la prosa poética, reconocía también sus peligros, entre ellos el afrancesamiento de la forma. ${ }^{20}$ La influencia de Paul Groussac ${ }^{21}$ sobre Darío of rece no pocos problemas para el investigador dariano. A pesar de que en "Los colores del estan-

18 Estudios, pp. 127-128.

19 "Los raros", en Ensayos sobre literatura latinoamericana, t. I (México, 1953), p. 82.

20 A este propósito dice E. Anderson Imbert: "Era consciente de los peligros de la prosa poética: uno, el guardar en cofre-decía-las perlas sueltas, en vez de hilvanarlas en collar de acciones; otro, el romper la gramática española a fuerza de intercalarle formas francesas (el remedio-apuntaba-es leer a Jovellanos, buen administrador de la lengua)". Ver Historia, t. I, p. 332.

Para Darío, como luego veremos, al afrancesamiento de la forma - en dosis moderada- no sería "peligro", sino aprovechoso medio para desentumecer la rancia prosa castellana de fines del siglo xix.

21 Paul Groussac (1848-1929), eminente escritor francoamericano, se destaca en la Argentina entre el grupo de los "hombres del. 80". "Fue, dice Anderson Imbert, un maestro de rigor crítico, de estudio disciplinado, de seriedad intelectual" '(Historia, I, p. 306). "En 1896, dice Max Henríquez Ureña, fundó la excelente revista $L_{a}$ Biblioteca, donde vieron la luz algunas producciones notables de los modernistas, como el Coloquio de los centauros, de Rubén Dario, y La voz conitra la roca, de Lugones" [Breve bistoria del modernismo (México, 1962), p. 174]. La Biblioteca dejó de publicarse en 1898. 
darte" (Buenos Aires, I896) Dario le atribuye una importancia singular en la formación de su propia prosa, ${ }^{22}$ nosotros creemos firmemente que Groussac no es sino uno de los muchos escritores americanos que el joven Dario admiraba en sus años de tutela literaria. De Groussac es esta profesión de fe artística: "Confieso que tendría por ideal literario (en América, se entiende) alcanzar la corrección gramatical española sin perder el contorno nítido y el andar nervioso del francés" ( $E l$ viaje intelectual, I, 13). ${ }^{23}$ Agreguemos a esto que Groussac, de origen francés, se hizo -irónicamente- uno de los puristas más rígidos de la lengua castellana. En sus "Versos de año nuevo" (Igro), Darío se ve obligado a criticar al "fino" disciplinista Groussac. Pensando seguramente en Groussac, dice Dario, con leve humor, que: "Mi verso exige un disector, / y un desinfectante mi prosa". ${ }^{24}$ No nos extrañaría si Groussac, como los severos académicos de la lengua, fuera de aquellos que se complacían en cazar los galicismos verbales y sintácticos del Rubén prosista.

En Chile, entre I886 y I889, Dario se vio circundado de una banda de escritores que seguían servilmente las fórmulas estéticas del Parnaso francés. El más importante de estos escritores, el que más influyó en Darío, fue el hijo del presidente de la República chilena, Pedro Balmaceda Toro. Este, cuyo pseudónimo literario fue "A, de Gilbett", era "suscriptor de revistas francesas de letras y dueño de una excelente biblioteca de 'amateur', y abrió a los ojos de su amigo nicaragüense todo un mundo nuevo $y$

22 A Groussac, en efecto, atribuye Darío su tutela para el "galicismo mental" en la prosa: "Cuando leía a Groussac no sabía que fuera un francés que escribiese en castellano, pero él me enseñó a pensar en francés". Ver. J. Saavedra Molina, Poesía y prosas rasas, p. 68. Semejante confesión, aunque más amplia en su comprensión, se encuentra en la Autobiografía de Datio: "He de manifestar que es en ese periódico [ $\mathrm{La}$ Nación] donde comprendí a mi manera el manejo del estilo y que en ese momento [durante su estancia en Chile] fueron mis maestros de prosa dos hombres muy diferentes: Paul Groussac y Santiago Estrada, además de José Martí. Seguramente en uno y otro existía el espíritu de Francia. Pero de un modo decidido, Groussac fue para mí el verdadero conductor intelectual" (Obras completas, t. XV, pp. 58-59).

No podemos menos que pensar que este enaltecimiento de la influencia de Groussac se debe a la "cortesía profesional". Ambos escritos, "Los colores del estandarte" y la Autobiografía, salen a luz en Buenos Aires, ciudad en que Grous. sac gozaba de muchísima importancia en los círculos intelectuales. No le gustaba a Darío, en efecto, cultivar enemistades; hacía todo lo posible para no agravar una incomprensión entre él y otro pensador de alta categotia. Véase con cuánta maña trata de disimular que sale ganando de la crítica adversa que Groussac hizo de Los raros (1896): "Yo he sido relativamente feliz. ¿Qué cosa hay más dulce que la miel y más fuerte que el león? Yo he encontrado miel en la boca del león, y del león vivo!" ("Los colores", p. 67).

23 Citado por Amado Alonso en "Paul Groussac, estilista", Materia y formia en poesia, pp. 398-399.

24 Poesías completas, p. 1163. 
exquisito". 25 Darío lo alaba muchísimo en su libro $A$. de Gilbert (r890): "Veis en el período del cuento una gallardía de expresión, un modo de decir las cosas gentilmente, peregrino en nuestra lengua. El cuento, este género sutil y peligroso, era para él fácil, y lo abordaba magníficamente".26 Pedro Balmaceda es autor de un libro de crítica literaria, Estudios i ensayos literarios ( 1899 ), cuya prosa se destaca por la nitidez y la claridad de su sintaxis; su ensayo (en el mismo libro) sobre la "Novela social contemporánea" muestra un gran conocimiento de los autores franceses de la segunda mitad del siglo xix:

En cuanto a escritores "artísticos" de España en la segunda mitad del siglo XIx, afirma Ãngel Valbuena Prat, con demasiada convicción, que "no existía un sentido de prosa poética, salvo el intento posromántico, aislado, de las 'leyendas' de Bécquer'. ${ }^{27}$ No. Además del consumado narrador Bécquer ( $1836-1870$ ), que quería "adornar con algunas galas de la poesía" la estructura de sus cuentos, tenemos que reconocer que había otros escritores que cultivaron, aunque con menos éxito, la prosa poética. En 1867, Eugenio de Ochoa publica un cuento muy lírico que se titula "Hilda, cuento fantástico"; según Mariano Baquero Goyanes, está escrito "en tono de balada germánica".28 En I872, Gaspar Núñez de Arce publica una narración, "Sancho Gil., cuento fantástico", cuya prosa está repleta de verdaderos versos. En I880, Juan Valera escribe su famosísimo cuento "fantástico", "El pájaro verde", rica fuente poética y decorativa para el cuento dariano, "El rey burgués". En varios cuentos de sus Narraciones inverosimiles, de 1882 , Pedro Antonio de Alarcón escribe en una prosa poética de "una cierta intención versicular". ${ }^{29}$ Basten estos ejemplos para demostrar que la segunda mitad del siglo XIX en España sí tuvo una buena cantidad de prosistas poéticos, de autores que trataron de escribir con esmero y arte. ${ }^{30}$

Es muy probable que Darío conociera la obra de todos estos prosistas

25 Raúl Silva Castro, "Introducción" a la Antología crítica del modernismo bispanoamericano (New York, 1963), p. 21.

26 Obras de juventud de Rubén Dario, ed. Armando Donoso (Santiago de Chile, 1927), p. 358.

27 Historia de la literatura española, III (Barcelona, 1957), p. 370.

28 El cuento español en el siglo XIX (Madrid, 1949), p. 239. p. 30 .

29 Guillermo Díaz-Plaja, El poema en prosa en España (Batcelona, 1956),

30 De particular interés para este tema es el capítulo VII del libro arriba citado de M. Baquero Goyanes. En este capítulo, que se titula "Cuentos fantásticos", el autor traza la influencia que tuvieron en España Hoffmann y Poe en la literatura imaginativa, "fantástica", del período romántico, post-romántico y realista. En el cuento "fantástico", la nota poética es de suma importancia; en muchos casos, el relato adopta una forma que es un compromiso entre el verso y la prosa. 
artísticos, tanto de América como de España. Un escritor tan ansioso de novedades como Darío no podía sino familiarizarse con otros artistas que demostraban intereses afines.

Ahora bien, escritores de esta índole artística se pierden en la gran masa de prosistas tradicionales que escriben sin preocuparse de la belleza formal de su prosa. Son estos prosistas, con su "chata y vulgarísima manera de escribir", ${ }^{31}$ quienes demuestran concretamente a Darío que ya es hora para una revolución literaria. $Y$ es en España, "amurallada" en su tradición, donde más hacía falta esta revolución, el "modernismo" - - revolución que luchaba contra el arte de pequeñas satisfacciones estéticas

En efecto, la literatura castellana de la segunda mitad del siglo Xrx ofrece, en su conjunto, un lamentable aspecto de pobreza estilística; se advierte en la mayor farte de los escritores una gran despreocupación para pulir su estilo, para hacer de él una cosa individual y no una manifestación mostrenca, nacional, casi común a todos los escritores. En este sentido, Ia época posromántica y realista no representa un gran avance estético sobre el período romántico anterior, período en que predominaba la expresión efectista y retórica. El "espíritu burgués" del periodo realista (I850_i887, según Cejador y Frauca) penetra en las letras; el arte se concibe como vehículo para entretener a la clase media; no se pretende crear obras de alto mérito formal. Los escritores nos describen, en un lenguaje tibio, familiar y regionalista, los temas que cuadran a su sed de reflejar fielmente lo costumbrista, lo local y lo cotidiano. Y la calidad de esa prosa costumbrista va, por lo general, al ras del suelo.

De ningún valor sería enumerar aquí el montón de prosistas regionales que escriben entre $185^{\circ}$ y 1887 ; el lector que quiera examinar esa selva oscura de la literatura castellana debiera acudir al segundo tomo de Costumbristas españoles (Madrid, 195I), de E. Correa Calderón. Bástenos recordar que esta es la época del apogeo de las novelas de folletín o "por entregas". Estas novelas son de pésimo gusto artístico, siendo su único propósito el de hacer pasar un buen rato a sus lectores. Algunos novelistas españoles de este género son: Julio Nombela (1836-I9I9), Manuel Fernández y González (I82I-I882), Enrique Pérez Escrich (I829-I897), y Ramón Ortega y Frías (r825-1883). En la obra voluminosa de estos

31 Díaz-Plaja, El poema en prosa en España, p. 30. 
prosistas, la cantidad vence a la calidad; a ellos les preocupa el éxito económico de las "entregas", no su valor estético. Las novelas por entregas no inundaron solamente la Península, sino también la América entera. En América, podemos citar como cultivadores de la novela folletinesca al mexicano Manuel Payno (I810-1894), al cubano Cirilo Villaverde (I812-1894), y al chileno José Antonio Torres (I928-I884).

Este cuadro de anquilosamiento estético se ve un tanto "iluminado" en América, ya que hay muchísimos prosistas que cultivan, a partir de I850, la prosa artística. En esa misma época, como ya hemos visto, España nos of rece un número menor de escritores que trabajan su prosa con arte. Esos prosistas artísticos representan una minoría de los que escriben.

Como fenómeno curioso, vamos a comparar a continuación un pasaje de la prosa "modernista" de $A z u l \ldots$ con la de un prosista "tradicional" que escribe en la misma época. Hemos elegido para esta comparación un pasaje descriptivo de la prosa novelística de José María de Pereda; por ser demasiado larga nos vemos obligados a reproducir solamente una parte de esa descripción. Lo que sigue es sólo una parte de la extensa descripción que hace Pereda de la huérfana Sotileza:

Porque yo recuerdo muy bien que lo primero que se echaba de ver en aquella garrida muchacha cuando estaba, a los veinte años, en la flor de su galanura, era la limpieza extremada de su atavío, en el que dominaban siempre las notas claras, como si esto fuera un alarde más de su pulcritud a prueba de peligros; y no emperejilada para las fiestas de la calle, o las bodas de la vecindad, o la misa o el paseo de los domingos, que esto probaría bien poco; sino todos los días, a la puerta de la bodega, en lo alto del Paredón, atravesada en la acera, tejiendo la red en el portal, sacando la barredura a la mitad del arroyo, o remendando los calzones de tío Mechelín; en refajo corto, descubriendo por debajo tres dedos de lienzo más blanco que la nieve; con justillo de mahón, rayado de azul, pañuelo de mil colores sobre el alto, curvo y macizo seno; a medio brazo las mangas de la camisa, y otro pañolito de seda, claro también, graciosamente atado, a la cofia, sobre el nutrido moño de su pelo de oro bruñido. ${ }^{32}$

(Sotileza, I884)

32 Obras completas de D. José Mariá de Pereda, t. IX (Madrid, 1900), p. 216. No faltan en las novelas de Pereda otros pasajes descriptivos de la misma índole: pobres en interés, llenos de frases hechas, enojosamente largas. No obs. tante, hemos escogido este pasaje no al "azar", como suelen hacer los grandes eruditos, sino con deliberada intención demostrativa. 
Como punto de comparación con la prosa descriptiva de Pereda, hemos escogido este pasaje descriptivo de "Palomas blancas y garzas morenas" (lindo cuento "erótico" de $A z u l$...). Lo que sigue es una descripción de la joven Inés, prima de Darío, de quien él se enamoró en su juventud:

Ya tenía quince años y medio Inés. La cabellera, dorada y luminosa, era un tesoro. Blanca y levemente amapolada, su cara era una creación murillesca, si se veía de frente. A veces, contemplando su perfil, pensaba en una soberbia medalla siracusana, en un rostro de princesa. El traje, corto antes, había descendido. El seno, firme y esponjado, era un ensueño oculto y supremo; la yoz clara y vibrante, las pupilas azules, inefables, la boca llena de fragancia de vida y de color de púrpura. ¡Sana y virginal primavera! 33

$$
\text { ("Azul...," I888) }
$$

Deslumbra la brevedad del pasaje de Darío frente a la agotadora descripción de Pereda. Pereda, narrador "realista", escribe en una prosa analítica que obedece a su deseo de pintar las cosas con verdad. "Tengo para mí, dice el novelista, que en esto de pintar con verdad, y por ende, con arte, no debe omitirse detalle que no huelgue". ${ }^{34}$ Pereda no ha omitido nada; en efecto, ha dicho demasiado. Feliz es el lector que pueda, al llegar al final del período, recordar los detalles descriptivos de los principios de la oración. Nótese, además, que la descripción se prolonga lánguidamente en un solo período. Fácil es que, en la lectura de este período, el lector se pierda en los nexos subordinados, en los "eslabones". Oraciones subordinadas, tales como "como si esto fuera un alarde más de su pulcritud a prueba de peligros" y "que esto probaría bien poco", no hacen sino quitar nuestra atención de los detalles más importantes de la descripción. Con harta razón se quejaba Dario en cierta ocasión de "esa onda lisa del periodo tradicional cuya superficie no arruga la menor sensación de arte, el menor impulso psíquico personal". 35

En el pasaje de Darío se ve cómo "la urdimbre recia y tupida de nuestro idioma pierde su densidad tradicional, y adquiere la levedad evanescente del encaje".36 Palabras acertadas, éstas de Rodó. No hay nada

33 J. Saavedra Molina y E. K. Mapes, Obras escogidas, t. I, pp. 279-280.

34. El sabor de la tierruca, t. $\mathrm{X}$ de las Obras completas, $\mathrm{p}, 104$.

35 "Los inmortales", en España contemporánea, p. 197.

36 José Enrique Rodó, "Rubén Darío", en Hombres de América (Barcelona, 1920), p. 125. Este estudio de Rodó apareció a manera de prólogo para la edición parisiense de Prosas profanas (1901). 
de denso, de tupido, en esta prosa de breves períodos. "Ud. hace gala de laconismo", había dicho Valera en su muy citado prólogo a $A z u l$... Con siete pinceladas rápidas, Darío ha pintado un cuadro de notable relieve artístico. Darío, poeta de corazón escribe en una prosa sintética; más bien que amontonar detalle sobre detalle, Darío ofrece al lector el número mínimo de detalles descriptivos. Confía en la facultad creadora e imaginativa del lector culto, del lector que sabe apreciar el valor de una alusión o de una buena imagen. Por ejemplo, la expresión "blanca y levemente amapolada, su cara era una creación murillesca", vale cien palabras descriptivas. Aunque las palabras "blanca y levemente amapolada" dicen bastante sobre el aspecto de la cara de Inés, esas palabras vienen reforzadas por la referencia a una "creación murillesca". No cabe duda de que Darío se refiere a las caras de las famosas Vírgenes del pintor andaluz. Quien haya visto una "Inmaculada Concepción" (p. ej., la de San Idelfonso) de Murillo sabrá sustituir por sí mismo otros detalles descriptivos que falten en el texto dariano: a saber, la inocencia, dulzura y candidez de esa cara, de contomo clásico, y de una serenidad absoluta...

Falta en nosotros la capacidad para hacer un detallado estudio del ritmo y de la "musicalidad" de ambos pasajes; es tema que agradaría a cualquier musicólogo calificado.37 Lo único que podemos decir es que el ritmo de la prosa de Pereda nos parece monótono y cansador; carece, por lo tanto, de una musicalidad artística. Invitamos al lector a que lea en voz alta el pasaje de Pereda para comprobar nuestro juicio. Desde las palabras "y no emperejilada" hasta las palabras finales "su pelo castaño de oro bruñido", la voz sigue en un ritmo de continua tentsión fisiológica; este estado de "suspensión" rítmica cansaría a cualquier recitador. No es así el pasaje de Darío. Sus frases se leen con muchísima facilidad. La suya es una prosa artística que trata de halagar al oído; escribe esta prosa un artífice que conoce el secreto de la armonia bajo todas las formas. 38

37 Nos referimos particularmente a los eminentes musicólogos, Samuel Gili Gaya y Eduardo M. Torner. G. Díaz-Plaza señala (en El poema en prosa en España, p. 14) dos trabajos fundamentales de ellos: (1) S. Gili Gaya, "Observaciones sobre el ritmo de la prosa española", en la revista Madrid, núm. 2 (Valen cia, 1937), pp. 59-63; (2) E. M. Torner, "Música y literatura, tres esquemas filológicos", en la revista Música, núm. 3 (Barcelona, marzo de 1938), pp. 7-20.

De mucho valor, además, son dos estudios de Amado Alonso en Materia y forma en poesia: "El ritmo en la prosa" y "La musicalidad de la prosa en Valle-Inclán".

38 El poeta alemán Heintich Heine (1797-1856) cree que hay que conocer bien la poesía para poder escribir una prosa musical de alto mérito: "Pour miex écrire une prose achevée, il faut posséder, entre autres, une grande virtuosité 
Finalmente, en el pasaje de Pereda nos chocan algunos clisés que son verdaderos fósiles de la expresión humana. He aquí a: "en la flor de su galanura"; "más blanco que la nieve"; "su pelo castaño de oro bruñido". ¿Cuántas veces se habían usado estas, o parecidas, expresiones en la literatura anterior! "El clisé verbal es dañoso, dice Darío, porque encierra en sí el clisé mental, y, juntos, perpetuan la anquilosis, la inmovilidad".39

Era ya hora de cambiar de gusto estético, de buscar lo nuevo, lo "moderno". Era ya hora de renovar la expresión literaria, de ennoblecerla, de "hacer del don humano por excelencia un medio refinado de expresión". "O rinnovarsi o morire".

Repetimos que la polémica de Darío, portaestandarte del movimiento modernista en España, va dirigida contra los prosistas que no cuidan de su estilo, que hacen del arte un pasatiempo burgués. En el curso de preparar este estudio hemos leído un valiosísimo artículo de Darío sobre "Novelas y novelistas" de España; este artículo, que se encuentra en España contemporánea, lleva por fecha el 24 de julio de r899. Aquí Darío nos revela sus juicios sobre los novelistas españoles finiseculares y encontramos una crítica muy acerba sobre la estética de Pereda. "Su estética, dice Darío, huele a viejo, su cuello se mantiene apretado en la anticuada almidonada golilla. Es un espíritu fósil, pero poco simpático a quien no tenga por ideal lo rancio y lo limitado. Hay que leer esa Sotileza que han traducido al francés, hay que leerla en el idioma extranjero para ver lo que queda en el esqueleto, despojado de sus afectaciones de dicción: un colosal y revuelto inventario". 40 A pesar de este juicio de Darío sobre Pereda, tenemos que reconocer que éste - y otros prosistas de la época- tenía mejores momentos de creación literaria. ${ }^{41}$ Valera es, sin duda, el más pulcro y elegante

dans les formes métriques: sans cela il manque an prosateur un certain tact, il lui échappe des associations de mots, des expressions, des césures et des tournures qui ne sont à leur place que dans la poésie, et il en résulte une secrète dissonance que ne blesse que peu d'oteilles, mais les plus fines". Citado por Ventura Garcia Calderón en "Rubén Darío", Mercure de France, CXIV, núm. 427 (1916), p. 390. En "Dilucidaciones" (prólogo a El canto errante, 1907), Darío nos tevela su afición por la expresión musical: "He querido ir hacia el porvenir, siempre bajo el divino imperio de la música -música de las ideas, música del verbo". (Poesias completas, p. 791).

39 "Dilucidaciones", El canto errante, en Poesías completas, p. 788.

40 Obras completas, t. XIX, p. 185.

41 Véase, por ejemplo el capítulo XXII de El sabor de la tierruca, titulado "Entreacto ruidoso". Aquí Pereda emplea todos los recursos dinámicos del lenguaje 
estilista de su tiempo. Sin embargo, la prosa de la última mitad del siglo $\mathrm{xxx}$ asombra por lo descuidado de la forma. En su conjunto, es una prosa sarmentosa, pesada, llena de clisés, carente de vigor e individualidad. Faltaba un espíritu rebelde como el de Darío para ridiculizar esa prosa estancada y para dirigir aquel movimiento reformador que, por falta de mejor nombre, llegó a llamarse "modernismo". Y bien se podría decir del modernismo lo que Hugo había dicho del romanticismo francés: es la revolución en la literatura. $Y$ aun más: "El modernismo, en cuanto movimiento artístico, es una evolución $y$, en cierto modo, un renacimiento". ${ }^{42} Y$ hay que reparar en que el modernismo no rechazó la herencia del pasado, sino que construyó sobre ella.

Volvamos a aquel manifiesto literario de la juventud de Darío, a ese artículo que lleva por título "Catulo Mendez. Parnasianos y decadentes". En este artículo Dario, en forma indirecta, nos da a entender sus deudas a los viejos artistas, a los clásicos de la lengua castellana; alaba los méritos de la lengua castellana y dice que tiene iguales, si no superiores, méritos intrínsecos que la lengua francesa:

Pocos se preocupan de la forma artística, del refinamiento; pocos dan - para producir la chispa-con el acero del estilo en esa piedra de la vieja lengua, enterrada en el tesoro escondido de los clásicos; pocos toman de Santa Teresa, la doctora, que retorcía y laminaba la frase; de Cervantes, que la desenvolvía armoniosamente; de Quevedo, que la fundía y vaciaba en caprichoso molde, de raras combinaciones gramaticales. $Y$ tenemos quizás más que ninguna otra

para describir el comienzo, crecimiento, climax, y fin de un huracán que se ariemete contra el pueblo de Cumbrales. Sobre esta escena dice una autora alemana: "Aquí se manifiesta todo su arte en las más sutiles acotaciones y la más grande diversidad de los medios de expresión que armonizan con el contenido de la escena y que pueden materializar a los grados más altos de la dinámica". La cita es de Gerda Outzen, El dinamismo en la obra de Pereda, trad. de Maria Fernanda de Pereda y Tcrres Quevedo (Santander, 1936), p. 239. También es de alto mérito el animado cuadro del capítulo XXVIII de Sotileza. A pesar de ciertas caídas en ese capítulo, el mar enfurecido está representado en unas páginas memorables.

42 Citamos de un trabajo de Eduardo López Chavarri, premiado por el semanario de Madrid, Gente Vieja. El trabajo debió salir a la luz en 1902, cuando este periódico hacia una encuesta sobre la naturaleza del modernismo: "Qué es el modernismo y qué significa como escuela dentro del arte en general y de la literatura en particular" Es interesante notar que el Jurado calificador estaba integrado por don Manuel del Palacio, don Benito Pérez. Galdós y don Jacinto Benavente. Debemos nuestros informes a $G$. Díaz-Plaja, Modernimo frente a Noventa y Ocbo (Madrid, 1951), pp. 35-36. 
lengua un mundo de sonoridad, de viveza, de coloración, de vigor, de amplitud, de dulzura; tenemos fuerza y gracia a maravilla. ${ }^{43}$

Aunque la lengua castellana tiene en sí "fuerza y gracia a maravilla", nuestra tesis es que esa fuerza y gracia andaba escondida, por lo general, en la prosa castellana "fin de siglo". Darío reconoce aquella pobreza estilística de la época y propone una solución, un programa de reforma literaria:

Se necesita que el ingenio saque del joyero antiguo el buen metal y la rica pedrería, para fundir, montar y pulir a capricho, volando al porvenir, dando novedad a la producción, con un decir flamante, rápido, eléctrico, por cuanto nunca se han tenido a la mano como ahora todos los elementos de la naturaleza y todas las grandezas del espiritu. ${ }^{44}$

¿Por dónde había que buscar "todos los elementos de la naturaleza y todas las grandezas del espíritu" que ahora, según Dario, estaban a la mano? Pues - digámoslo francamente-, en los escritores franceses del momento, en esos artífices que explotaban todas las posibilidades de su idioma. No negamos la importancia de los "precursores" de Darío en la formación de su propia prosa artística; en verdad, hay un crítico que afirma categóricamente (y con demasiada presunción) que "sin Martí, no hay Darío".45 Sin embargo, nosotros creemos que Dario debe más a los estilistas fran-

43 Silva Castro, Obras desconocidas, p. 171. No se le puede acusar a Dario de no conocer bien a los clásicos españoles. Su obra total muestra todo lo contrario. En su Autobiografía Darío nos explica cómo, en un empleo en la Biblioteca Nacional de Managua, aprovechó esa coyuntura para ahondarse en los clásicos de la lengua: "Allí pasé largos meses leyendo todo lo posible y entre todas las cosas que leí iborrendo referens! fueron las introducciones de la Biblioteca de Autores Españoles de Rivadeneira, y las principales obras de casi todos los clásicos de nuestra lengua". Ver t. XV de las Obras completas, p. 33.

44 Silva Castro, op. cit., p. 33 El subrayado es nuestro.

45 El crítico al que nos referimos es Osvaldo Bazil. Al leer un estudio de Manuel Pedro González, "La revaloración de Marti", en Estudios sobre literaturas bispanoamericanas (México, 1951), nos chocó encontrar dicha frase categórica en la página 143. González hace una breve reseña de un folleto que publicó Bazil en La Habana en 1932. Este estudio de Bazil se rotula — como bien ha indicado González- "impropiamente" Vidas de iluminatión y comprende dos ensayos: "La huella de Martí en Rubén Dario" y "Cómo era Rubén Darío". El primer ensayo, el que nos interesa, se puede encontrat también en el libro Rubén Dario y sus amigos dominicanos (Bogotá, 1948). No hemos podido con sultar este ensayo de Bazil, pero nos sería grato hacerlo algún día. 
ceses de su tiempo que a los escritores - "precursores" o contemporáneosde su propia lengua.

Son los prosistas franceses de la época - con su afán de perfección formal y su predilección por el color y la música de la frase-quienes cautivan, definitivamente, al espíritu de Darío. No hay que buscar en la obra de tal o cual escritor francés la fuente directa de los procedimientos estilísticos de Darío. De todos ha tomado, de todos ha aprendido lo que cuadraba a su "sed de novedad" y a su "delirio de arte". De todos estos estilistas franceses, el gran nicaragüense pudo sacar, en las palabras de Valera, una "rara quinta esencia". Y en su libro $A z u l$... Darío resultó original.

A pesar de que Darío en muchas ocasiones nos da datos incompletos, o bien inexactos, sobre sus fuentes de inspiración, no podemos negar la verdad y la sinceridad de estas palabras suyas en torno a sus propósitos de renovar la lengua castellana por vía francesa:

Mi adoración por Francia fue, desde mis primeros pasos espirituales, honda e inmensa. Mi sueño era escribir en lengua francesa. $Y$ aun versos cometí en ella que merecen perdón, porque no se han vuelto a repetir... Al penetrar en ciertos secretos de armonía, de matiz, de sugestión, que hay en la lengua de Francia, fue mi pensamiento descubrirlos en español, o aplicarlos. La sonoridad oratoria, los cobres castellanos, sus fogosidades, ¿por qué no podrían adquirir las notas intermedias, $y$ revestir las ideas indecisas en que el alma tiende a manifestarse con mayor frecuencia? Luego, ambos idiomas están, por decirlo así, construídos con el mismo material. En cuanto a la forma, en ambos puede haber idénticos artífices. 46

Si bien su admiración por la lengua francesa hizo que Darío incurriera en galicismos, tanto mentales como lingüísticos, ${ }^{47}$ no es de dudar que esa misma admiración por la estructura de la lengua hermana ejerció una grandísimia influencia en la renovación de la prosa castellana. A nuestro parecer, el "galicismo mental" de Dario despertó el individualismo de los prosistas de la lengua castellana, les enseñó a apartarse de la prosa indisciplinada y uniforme que abundaba en la literatura castellana de fines

46 "Los colores del estandarte", en Poesias y prosas raras, ed. J. Saavedra Molina, p. 68.

${ }_{47}$ Ver Juan López-Morillas, "El Azul de Rubén Darío. ¿Galicismo mental o lingüístico?", en $R H M, X$, núms. 1 y 2 (1944), pp. 9-14. 
del siglo xix. También es de atribuir al galicismo "mental" de Azul... el desmembramiento de la larga frase clásica castellana, pomposa y altisonante. ${ }^{48}$ Con Juan López-Morillas, nosotros creemos que los galicismos lingüísticos - sintácticos y verbales - de $A z u l$. . . están hechos con "pleno conocimiento de causa". ${ }^{49}$ Los galicismos lingüísticos nunca llegan al extremo en $A z u l$... Leemos, sí, una prosa un tanto afrancesada, pero el lenguaje, por lo general, "persiste español, legítimo y de buena ley". ${ }^{50}$ Fsos galicismos lingüisticos, para usar una palabra de Valera, están hechos "adrede". Bien sabía Darío - y esto decimos a despecho de los "puristas" de la lengua-que "la belleza y la gramática son enemigas". 51 Añádase, también, que no hay ningún idioma "puro", ningún idioma que no pueda enriquecerse con la introducción mesurada de voces y locuciones extranjeras.

Aunque se ha achacado a Darío ser "corruptor" de la lengua castellana a causa de su afrancesamiento, nuestra actitud frente a este innovador en la prosa es más benévola. La prosa castellana sale ganando muchísimo por la imitación de los modos sintácticos del francés; la persistencia en el uso de las anquilosadas maneras expresivas de los siglos anteriores habría sido catastrófica. Para consolar a los intransigentes "puristas", vamos a citar las palabras de "Azorín" sobre la naturaleza de una renovación literaria: "Ni un artista, ni una sociedad de artistas, podrán renovarse--ser algo-o renovar el arte, sin una influencia extraña". ${ }^{52}$

A veces, también, la aportación de voces nuevas es absolutamente necesaria. ¿Para qué rechazarlas en nombre del "purismo"? Un crítico que escribe en 1906 defiende de esta manera la introducción de palabras francesas en el léxico español:

Hay muchísimas ideas y objetos que no tienen palabras que los tra-

48 López-Morillas, op. cit., p. 12.

49 Ibid.

50 Citamos del prólogo a Azul ... de Valera, en J. Saavedra Molina y E. K. Mapes, Obras escogidas, p. 200.

51 Es hecho que se comprueba en la obra de los más atildados parnasianos, como los Goncourt, Flaubert, Mendès. No queremos decir, sin embargo, que todo buen escritor debe escribir no haciendo caso de los preceptos de la gramática. No. A veces, el escritor es capaz de extralimitarse de esos preceptos y crear una obra bella, sólida y de buen gusto, a pesar de su intransigenciat con la gramática. Además, como dice el famoso lingüista norteamericano Edward Sapir: "Were a language ever completely 'grammastical', it would be a perfect engine of conceptual expression. Unfortunately, or luckily, no language is tyrannically consistent. All grammars leak". Ver Litnguage (New York, 1949), p. 38.

52 "La generación de 1898", en Clásicos y modernos, t. II de las Obras completas (Madrid, 1947), p. 908. 
duzcan con precisión y rapidez en español. "Boudoir", prélèvement", "chalet", "enhardir", etc., carecen de equivalente. Muchas veces hay que dar un rodeo y servirse de numerosas palabras para indicar una cosa que se dice en dos sílabas en francés o en inglés. Otras hay que emplear expresiones absurdas como "mechero de gas" para designar el pico de luz de un sistema de alumbrado que ha hecho casualmente innecesaria la mecha. Para ser breves, muchos escritores jóvenes se han visto obligados a adoptar voces que no contiene el diccionario, como "bulevar", etc. Porque, después de todo, no es lo propio que las ideas estén al servicio del lenguaje, sino el lenguaje al servicio de las ideas.53

En resumen, más bien que llamar el lenguaje de Darío - y de otros modernistas - un lenguaje afrancesado, nosotros optamos por la denominación del "neo-español". ${ }^{44}$ Es decir, un español más flexible, más rico en giros y vocablos nuevos, libre de la tiranía absoluta de la gramática.

53 Manuel Ugarte, "Prefacio". a La joven literatura bispanoamericana. (París, 1906), p. XXX.

54 Es la expresión que empleó Remy de Gourmont, crítico del Mercure de France, para designar la lengua castellana que se cultivaba en América a principios de este siglo. La expresión fue rechazada abiertamente por Miguel de Unaimuno, el cual prefería decit que la lengua de América era una lengua sobremanera afrancesada. En un breve ensayo titulado "La cuestión del neo-español" (1904), en Letras y letrados de Hispano-América (París, 1908), Rufino BlancoFombona dice con mucho orgullo: "Basta conocer un poco, muy poco, el castellano, para darse cuenta, por el mero lenguaje, de si un libro fue escrito en. América o en España... La tevolución que hemos cumplido ha sido dentro del carácter y alma de nuestra preciosísima lengua. La diferencia entre nosotros y los peninsulares es sólo de progreso: es la diferencia que existe, por ejemplo, .... entre el lenguaje que se usa en la tercera República y el que se usaba en tiempo de la Fronda" (pp. 130-131). Afirmación que vale-con algunas reservas-para la época en que se escribió, pero que hoy día no tiene valor alguno, ya que los escritores actuales de España escriben con un lenguaje al día, muy "siglo $\mathrm{xx}$ ".

Enrique Díez-Canedo, en su discurso de recepción en la Academia Española el $1^{\circ}$ de diciembre de 1935, niega que haya existido una diferencia de progreso entre el castellano del Nuevo Mundo y el de España. Dice: "Grave error entre los que, considerando al español de América como en proğreso y avance sobre el de España, llegaron a pensar que el castellano en Castilla se había quedado inmóvil, momificado, mientras en los países nuevos crecía suelto y flexible, des. preocupado y abierto a influjos de modernidad, lengua viva y no triste, aunque venerable, lengua muerta". Ver" "Unidad y diversidad de las letras hispánicas", en Letras de América (México, 1944), p. 31.

Quizá Díez-Canedo muestre más prejuicios de los que él critica. El castellano de América, a nuestro parecer, sí estaba abiertó a "influjos de modernidad" desd su emancipación del yugo español que se llevó a cabo con las Guerras de Independencia. Ya no dominaba la influencia española tanto como antes. El hombre americano se entregaba, a pasos medidos, a un nuevo tutor intelectual, Francia. Los escritores franceses - nuevos "ídolos" de los literatos americanos- se distinguian por su libertad artística. De ellos, según Manuel Ugarte, "la intelec- 
Hasta ahora, hemos enfocado toda nuestra atención en el Darío innovador del libro Azul... Es necesario advertir, sin embargo, que Darío muestra sus más altos dones de prosista en otros libros (posteriores a Azul...) no deliberadamente poéticos. Decimos "no deliberadamente poétıcos" porque Dario muchas veces infunde, sin hacerlo de propósito, un "clima" de poesía en su prosa; es difícil separar al prosista del poeta. En muchísimos pasajes, la prosa de Darío y de los demás modernistas da categoría literaria a una nueva entidad, muy en boga en nuestros días: el "poema en prosa".s5

Los libros a que nos referimos son: Los raros (1896), A. de Gilbert (I890), Castelar (I899), España contemporáned (I901), Peregrinaciones (I901), La caravana pasa (1903), Tierras solares (1904), Opiniones (1906), Parisiana (1907), El viaje a Nicaragua (I.909), Letras (I9I I), Todo al vuelo (I9r2), La vida de Rubén Dario escrita por él mismo (I9r2), Historia de mis libros (I9I3) y Cabezas (I9I6). Hemos dado la fecha de las primeras ediciones de estos libros.

En estos libros en prosa vemos cómo Dario ha podido transformar la lengua castellana en un instrumento flexible y vivaz, disponible a expresar los más finos matices del pensamiento. El prosista Darío ha triunfado sobre los lugares comunes del período realista. El estilo ampuloso, complejo y lento del periodo realista - véase la prosa de Zorrilla, Pereda, Castelar, Menéndez y Pelayo-- se ve sustituído por un estilo sencillo, rápido, de breves períodos y de una música suave. Darío, imitando a los estilistas franceses, repudia las largas frases de tradición clásica, con sus muchas oraciones subordinadas, sus "eslabones"; escribe directamente, sirviéndose, por lo general, de oraciones coordinadas. Nadie mejor que "Azorín" ha podido defender el estilo directo. "Poner una cosa, nos dice "Azorín",

tualidad sudamericana cobró una flexibilidad, una amplitud, una frescura, un atrevimiento, una independencia y sobre todo una atrayente novedad de estilo que, aun en aquellas épocas en que la producción literaria era suficiente y elemental, anuncia la concisión, la brevedad, el matiz y la fuerza de hoy" (La joven lite. ratura, p. XVII). En estas condiciones, es cierto que el castellano de América hacia fines del siglo pasado (digamos entre 1880 y 1900 , más o menos) sí era diferente, más en progreso, que el castellano de España.

55 Diaz-Plaja define de esta manera el "poema en prosa": "Denominamos "poema en prosa" toda entidad literaria que se proponga alcanzar el clima espi. ritual y la unidad estética del poema sin utilizar los procedimientos del verso". Ver El poema en prosa en España, p. 3. 
después de otra y no mirar a los lados". ${ }^{56}$ Los muchos incisos, o mejor dicho, "interrupciones", de una prosa amplia nos cansan. En fin, "es superfluo todo lo que dificulte la marcha del pensamiento escrito". .57

Quien tenga el prejuicio de que el modernismo en la prosa siempre representa un lenguaje florido, suntuoso y sensual se verá desmentido al leer las páginas de los últimos libros de Darío, en particular los que se escriben a partir de 1900.58 El lenguaje es siempre "aristocrático" (en oposición a "vulgar"), pero no es el Darío de la prosa de Azul... que confrontamos. En esta prosa periodística, "autobiográfica", y crítica, Dario ha dejado atrás esa prosa sencilla en la sintaxis, pero "afeitada" en el léxico. Cierto es que hay pasajes "retóricos" en estos libros en prosa, ¿pero quién no escribe con retórica? G. Díaz-Plaja, por una muestra de un solo pasaje "retórico" de Tierras solares, nos da la falsa impresión de que todo el libro es un ejemplo de periodismo estridente..$^{59} \mathrm{~A}$ nuestro parecer, el modernismo en la prosa de Darío es una batalla, una batalla a sangre y fuego, contra el retoricismo y academicismo de la prosa "realista" anterior. Se ha sustituído, sí, la retórica amplificadora por una retórica menor, la de la sencillez en la expresión. En suma, no confundamos al prosista Darío de los últimos años con el flamante prosista Rodó de Ariel (I900), ni con el exquisito esteta Valle-Inclán de las Sonatas (r902-1905). Estos son "modernistas" pero van por sus propios caminos.

Por fin, llega la hora de preguntarnos: ¿Cuál es la relación que existe entre el modernismo y la llamada generación del 98? ¿Cómo vamos a situar a Dario frente al 98? En I9I9, Julio Cejador y Frauca, quizá el historiador más mordaz del modernismo, no hace distinción alguna entre el 98 y el modernismo; para él son una sola entidad. Dice el crítico español: "Los principales de esta generación del 98 fueron "Azorín", Ramiro de Maeztu, Unamuno, Manuel Bueno, José Ortega y Gasset, Pío Baroja,

56 "Estilística", en El artista y el estilo, ed. Ángel Cruz Rueda (Madrid. 1946), p. 204. El ensayo de "Azorín" es de 1945.

57 lbid.

58 iCuánta diferencia hay entre el prosista de Los raros (1896), por ejemplo, y el prosista de Parisiana (1907)! En Los raros, Dario sí es, en muchos pasajes, el prosista florido, grandilocuente, retoricista (véase, p. ej., el ensayo sobre José Martí); parece que la prosa de Darío se hace tempestuosa cuando se deja arre. batar por los "raros" que conquistaron su alma. Pero en Psrisiana se muestra como el estilista fino, delicado, sencillo, a lo Catulle Mèndes. Desconcierta ver esta inclinación a lo efectista en el prosista que, repetidas veces, se decía el campeón contra los cánones de la retórica. Sin embargo, la prosa de Los raros lleva un inconfundible sello personal, vigoroso.

59 Modenismo frente a Noventa y Ocbo, pp. 312-313. 
Valle-Inclán, Marquina, los modernistas todos".60 EI mismo crítico hasta llega a decir que el modernismo es la "propia obra" de la generación del 98.61

Hoy dia ha sido puesto bien en claro, en particular por G. Díaz-Plaja, Pedro Salinas, y Melchor Fernández Almagro, ${ }^{62}$ que el modernismo y la generación del 98 no son una, sino dos generaciones, distintas en su tono $y$ en su alcance. En general, el modernismo es un movimiento casi exclusivamente artístico, mientras que el 98 pretende revisar todos los valores intelectuales: lo estético, lo moral, lo político, lo económico... Sin embargo, es necesario insistir en que entre el modernismo y la generación del 98 no existe una absoluta separación; las dos entidades no se excluyen mutuamente. Revisando y amplificando sus juicios de "El problema del modernismo en España, o un conflicto entre dos espíritus" (1938), Pedro Salinas ha dicho más recientemente lo que sigue: "Errónea y artificiosa es la tentativa de dividir tajantemente a los autores del nuevo siglo en dos campos cerrados, Modernismo y 98 , porque tanto una modalidad como la otra laten en todos y a todos animan. La diferencia es pura cuestión de posología: en tal autor la dosis 98 predominará notablemente sobre la modernista, en otro sucederá a la inversa".63

En su, artículo, "El españolismo en la obra de Rubén Darío", Ángel del Río nos señala cómo los hombres del modernismo y los del 98 forman una alianza espiritual contra los valores estéticos de la literatura "vulgar" y academicista del siglo XIx: "En éstos [los modernistas] como en los escritores de la peninsula hay la misma rebeldía frente a la literatura vulgat y absurda del siglo diecinueve, el mismo amor por las más avan-

60. Historia de la lengua y literatura castellana, t. X (Madrid, 1919), p. 50. Hemos subrayado lo conveniente.

61 Historia, p. 52. Nótese, también, que "Azorín", originador, si no nos engañamos, de la expresión "Generación de Noventa y Ocho", tampoco hace división fija entre "modernistas" y "noventayochistas". En efecto, incluye a Darío en la generación del 98 . Ver "La generación de 1898", en Clásicos y modernos, p. 911.

62 Nos referimos a tres estudios fundamentales de estos críticos: de G. Diaz-Plaja, Modernismo frente a Noventa y Ocbo; de Pedro Salinas, "El pro. blema del modernismo en España, o un conflicto entre dos espíritus", en Literatura española Siglo XX (México, 1949); de M. Fernández Almagro, Vida $y$ literatura de Valle-Inclan (Madrid, 1941), esp. pp. 56-57. El defensor más apasionado de la existencia de dos "generaciones". es, por cierto, G. Díaz-Plaja. 63 "Significación del esperpento o Valle-Inclán, hijo pródigo del 98"; en Literatura española Siglo XX (1949, segunda edición), p. 87. En la afirmación de Salinas se puede entrever una crítica del clasificador absolutista que es el G. Diaz-Plaja del Modernismo frente al Noventa y Ocho. El ensayo de Salinas sobre Valle-Inclán se publicó por primera vez en Cuadernos americanos, XXXII, (marzo-abril, 1947), pp. 218-244. 
zadas tendencias de las literaturas europeas, el mismo espíritu revolucionario, el mismo prurito por huir de la falsa retórica de los Balart y los Grilo, la misma apetencia intelectualista y las mismas antitéticas inquietudes". ${ }^{64}$ Pedro Salinas opina que tal alianza contra el "enemigo común" duró unos diez años, es decir, la primera década del siglo xx. ${ }^{65}$ Luego, los "aliados temporales, modernismo y generación del 98 , rompieron, en natural obediencia a sus distintas razones de ser". ${ }^{66}$

No nos corresponde aquí escudriñar cuáles hombres del 98 mostraron afinidades modernistas ni, viceversa, cuáles "modernistas" mostraron una preocupación por "el problema de España". ${ }^{67}$ Lo único que nos interesa subrayar es que, juntos, los noventayochistas y los modernistas llevaron a cabo la renovación de la prosa castellana, renovación que-como

64 Bulletin of Spanish Studies, II, núm. 5 (1924), p. 16.

65 "El problema del modernismo en España", en la obra citada, p. 24. 66 Ibid.

67 Es un mito creer que los modernistas, puestos en su "torre de marfil", no se preocupaban en absoluto de problemas políticos o sociológicos. Es mito que resulta de un afán de poner conceptos literarios en clasificaciones "matemáticas". ¿Quién va a decir que a Darío no le preocupa "el problema de España? Léase ese libro de reportaje que se titula España contemporáned (1901) y se verá a través de sus páginas que Darío no es el observador desinteresado que algunos críticos -en particular el Díaz-Plaja de Modernismo frente a Noventa y Ocbo-siempre ponen de relieve. El attículo "Carnaval" (que lleva la fecha del 17 de febrero de 1899) muestra bien a las claras al Darío de intereses nacionales: "Hay que abrir todas las ventanas para que los vientos del mundo barran polvos y telarañas y queden limpias las gloriosas armaduras y los oros de los estandartes; hay que ir por el trabajo y la iniciación en las artes y empresas de la vida moderna, 'hacia otra España', como dice en un reciente libro un vasco bravísimo y fuerte -el señor Maeztu..."Ver Obras completas, t. XIX, p. 67. En 1898 (antes de marcharse para España) Darío escribe un violento artículo contra el vencedos de las flotas españolas en las aguas de Santiago de Cuba. El artículo, que lleva el título de "El triunfo de Calibán", se publica primero en El Tiempo de Buenos Aires y luego lo reproduce La Época de Madrid, el 20 de agosto de 1898. Es una sátira mordaz de los "calibanes" norteamericanos, de los "niños salvajes" que crecen materialmente con pasos gigantescos. En este artículo Darí- - "hijo de América y nieto de España", como él mismo se declara una vez- revela su hondo amor y preocupación por España. "La España que yo defiendo, proclama, se llama Hidalguía, Ideal, Nobleza; se llama Cervantes, Quevedo, Góngora, Graciản, Velázquez; se llama el Cid, Loyola, Isabel; se llama la hija de Roma, la hermana de Francia, la madre de América". Ver Melchor Fernández Almagro, En tomo al 98. Politica y literatura (Madrid. 1948), pp. 145-149.

¡Con cuánto arte tratan los críticos de hacer olvidar sus juicios juveniles! G. Díaz-Plaja, en una obra de juventud Rubén Dario (Barcelona, 1930), dice sin rodeos de Dario: "No creo que se me tache de una rubenofilia excesiva si proclamo que Rubén Dario es - con Jacinto Benavente- el más auténtico representante de la generación del Noventa y Ocho" (p. S4). En Modernismo frente a Noventa y Ocbo, Díaz-Plaja no concede en ningún lugar que antes de 1951 él mantenía una posición radicalmente distinta de la presente. ¿Disimulo intencionado? Su juicio de 1930 tiene esto de cierto: Darío sí se puede incluir, a causa de su gran preocupación por el porvenir de España, en el 98. 
señalamos al principio de este ensayo- se esperaba desde hacía dos centurias. Gran acontecimiento, para el cual nosotros consideramos a Darío no sólo como un "precursor" sino como uno de los "motores" más importantes. Así como el modernismo, "la generación del 98 proclama la neçesidad de una vuelta a la sencillez, a la sinceridad, a la frase viva y expresiva". ${ }^{68} \mathrm{Y}$, como dice tan bien Gonzalo Torrente Ballester, "sin él [Dario], la evolución estética de la generación [del 98] se hubiera retrasado, y quizá recluída en sí misma, hubiera finalmente adolecido del casticismo, $\tan$ lejano a sus iniciales proyectos". ${ }^{69}$

Tanto el modernismo como la generación del 98 muestran la necesidad del escritor de descubrirse a sí mismo, de romper con la santa tradición de crear un estilo personal. Hablando del 98, dice J. García López: "Consecuencia del fuerte subjetivismo de estos escritores es el hecho de que cada uno de ellos presenta un estilo personal claramente diferenciado del de los demás, en contraste con el tono más o menos uniforme de la prosa del período anterior". ${ }^{70}$ Y Ramón María del ValleInclán, en su prólogo a Corte de amor, defiende la estética modernista de este modo:

De esta manera hice mi profesión de fe modernista: Buscarme en mí mismo y no en los otros. Porque esa escuela literaria tan combatida no es otra cosa. Si han caído sobre ella toda suerte de anatemas, es tan sólo porque le falta la tradición. Las obras que los críticos admiran sin protesta, y que todos los hombres admiran, son aquellas que cuentan cientos de años, y que nadie examina, porque ya tienen la sanción universal. Si en literatura existe algo que pueda recibir el nombre de modernismo, es, ciertamente, un vivo anbelo de personalidad...71

En muchos pasajes de sus obras, en particular en los prólogos a sus libros más importantes, Rubén Darío se jacta de la influencia que tuvo su libro Azul... en el rumbo de las letras castellanas. En el "Prefacio" a Cantos de vida y esperanza (Madrid, I905), Darío dice sin rodeos:

68 José Garcia López, Historia de la literatura española (Barcelona, 1959), p. 487.

69 Panorama de la literatura española contemponanea (Madrid, 1956), p. 127.

30 Historia, p. 487.

71 Operc omnia, t. XI (Madrid, 1914). [Este ensayo se publicó por primera vez en La Ilistración Española y Americant, el 22 de febrero de 1902]. Hemos subrayado lo conveniente. 
"El movimiento de libertad que me tocó iniciat en América se propagó hasta España, y tanto aquí como allá el triunfo está logrado".72 En "Dilucidaciones" (prólogo a El canto errante, Madrid, I907), Dario habla de la "pequeña obra primigenia que inició allá en América la manera de pensar y escribir que hoy suscita, aqui y allá, ya inefables, ya truculentas controversias". ${ }^{73}$ En "Los colores del estandarte" (Buenos Aires, 1896), Darío habla del "pequeño libro que iniciara el actual movimiento literario americano, del cual saldrá, según José María de Heredia, el renacimiento mental de España". ${ }^{74} \mathrm{Y}$, finalmente, en su historia del libro $A z u l . .$. , de I9I3, Darío no siente la menor dificultad en decir: "Si el librito tenía algún personal mérito relativo, de allí debía derivar toda nuestra futura revolución intelectual". ${ }^{75}$

Estas palabras de Darío son un tanto ambiguas y pretensiosas. En lo que toca a lo literario, no creemos que Dario se haya extralimitado. Pero, ¿hemos de pensar que el libro $A z u l$... encendió la chispa para el "renacimiento mental" de España? ¿Hemos de pensar que el modernismo americano es la causa de la fecundación del espíritu nacional que representa la generación del 98? De ninguna manera. Negamos asimismo, por ser demasiado generalizadas, estas palabras efusivas del dariísta Julio Saavedra Molina: "Aquel puñado de nieve $[A z u l$... $]$ cogido en la cima vecina al cielo azul, lanzado por la pendiente a la senda de nuestros pueblos, y engrosado con los aportes de otros cien visionarios, precedió y tuvo ciertamente su parte en la avalancha final de libros, de ideas, de reformas, de renovación, tanto literaria, como filosófica, como política, que todavía hoy vive el mundo castellano". ${ }^{76}$ ¿Qué tiene que ver el libro Azul... con la filosofía y la política que "hoy vive el mundo castellano"?

Nosotros creemos que es mejor entender el modernismo en el sentido estricto, limitando su alcance a lo artístico, a lo estético. Aunque el modernismo haya resultado del auge de liberalismo que surgió en América a partir de las Guerras de Independencia, se manifestó sobre todo-reconozcámoslo- como un movimiento artístico. El modernismo americano es sólo un antecedente de la libertad artística que iba a ser el ideal de los noventayochistas; no es la razón de ser de su actitud vital ante el "problema de España".

72 Poesías completas, p. 703.

73 Ibid., p. 790.

74 Poesia y prosas raras, p. 69. Lo subrayado es nuestro.

75 Historia de mis libros, p. 173.

76 Obras escogidas, pp. 146-147. 
Sin embargo, Dario ocupa un lugar innegable en las letras castellanas: el del innovador. $Y$ recordemos que la tentativa para renovar la prosa castellana se efectuó en América antes que en España; Azal ... marca un momento crítico en esas tentativas para renovar la prosa castellana. A nuestro parecer, la renovación que Darío llevó a la prosa castellana es tan importante como la que realizó en las formas métricas de la poesía.

Con mucho acierto ha dicho un crítico español que "la heroica audacia de Rubén Darío ha sido una magna operación vital en la lengua caste. Ilana"."7 Es Darío quien, en su segunda visita a la peninsula en I899, achaca a los jóvenes escritores su "abulia" en cuanto a las formas artísticas. He aquí sus propias palabras, no exentas de un tono de irritación:

Ahora, en la juventud que tiende a todo lo nuevo falta la virtud del deseo, o mejor, del entusiasmo, una pasión en arte, y sobre todo, el don de la voluntad. Además, la poca difusión de los idiomas extranjeros, la ninguna atención que por lo general dedica la Prensa. a las manifestaciones de vida mental de otras naciones, como no sean aquellas que atañen al gran público; y después de todo, el imperio de la pereza y de la burla, hacen que apenas existan señaladas individualidades que tomen el arte en todo su integral valor. En una visita que he hecho recientemente al nuevo académico Jacinto Octavio Picón, me decía este meritísimo escritor: "Créame usted, en España nos sobran talentos; lo que nos falta son voluntades y caracteres". ${ }^{76}$

En su papel como estimulador de la voluntad artistica de los nuevos escritores de España, se puede considerar a Darío, en las palabras de "Andrenio", como "una figura literaria que fue, más que continental,

77 José Carner, "La obra del mago", en La ofrenda de España a Rubén Dario (Madrid, 1916), p. 167.

78 "El modernismo", en España contemporánea, pp. 269-270. También debió sentirse la influencia de Darío, aunque en tono menor, en 1892, año de su primet viaje a la península. Tenía entonces Darío veinticinco años. A un redactor de La Ilustración Española $y$ Americana, habla en su propia defensa contra los que le acusan de "corruptor" del idioma y reclama la necesidad para un "renacimiento" artístico. Sus propias palabras, según M. Fernández Almagro: "Entiéndase que nadie ama con más entusiasmo que yo nuestra lengua y que soy enemigo de los que corrompen el idioma; pero desearía para nuestra Literatura un renacimiento que tuviera por base el clasicismo puro y marmóreo en la forma, y con pensamientos nuevos; lo de Chénier, llevado a milyor altura: arte, arte, arte". Vet En torno al 98 , p. 140 . 
producto de la raza, y en su esfera, mentor espiritual de ella".79 En la persona de Rubén Datío, en suma, España descubrió por segunda vez. a América.

University of Califomia at Berkeley

JOSEPH V. JUDICINI

79 "El precursor"; en La ofrenda, p. 133. 
